\title{
40 anos de política externa brasileira, 1958-1998: três inflexões
}

\author{
EIITI SATO*
}

Este trabalho não pretende enumerar o que houve de relevante na política externa brasileira em termos fatuais, mas sim tentar identificar inflexões ou mudanças significativas ocorridos nos padrões de relacionamento externo do País ao longo dos últimos 40 anos. Procurar-se-á, na medida do possível, cotejar essas mudanças tanto com a conjuntura internacional quanto com as condições políticas e econômicas internas. Nessa perspectiva, duas facetas ou vertentes podem ser estabelecidas, no âmbito das quais as relações externas brasileiras foram sendo ajustadas: de um lado, a inserção econômica internacional do Brasil e, de outro, as relações do País com a agenda de segurança internacional. Em termos teóricos, pode-se dizer que, ao menos como ponto de partida, toma-se emprestado do realismo político a clássica dicotomia entre "low politics” e "high politics”. Esse corte de análise ajuda no entendimento do que pode ter ocorrido com os padrões de associação externa do País: as relações com os Estados Unidos, com a Argentina e os países da região, até a crescente importância do multilateralismo e das relações globais, num ambiente em que, paradoxalmente, o poder da ação do Estado sofre erosão em muitos aspectos tradicionais. Nessa perspectiva, pelo menos três inflexões ou mudanças centrais podem ser identificadas no período que vai desde o Governo JK até nossos dias: o abandono do "Paradigma Rio-Branco", que colocava os EUA como centro pivotal da política externa brasileira; a ampliação das opções de parcerias internacionais associada ao aumento e diversificação da base econômica; e a crescente importância do multilateralismo num contexto de globalização.

\section{O abandono do Paradigma Rio-Branco}

O Governo JK pode ser dividido em duas fases distintas: até 1957, quando o País viveu um período de grande otimismo desenvolvimentista, e de 1958 até o fim do mandato, que foi um período marcado por dificuldades externas onde as negociações com os Estados Unidos se mostravam difíceis e pouco produtivas. De um lado, havia problemas com o endividamento externo e com as limitações de uma economia pouco diversificada, em estágio precário de industrialização, enquanto, de outro, os Estados Unidos passavam a se preocupar com questões mundiais, deixando as relações regionais em segundo plano. Essa conjuntura deve 
ser, em grande medida, considerada como produto das condições políticas e econômicas do pós-guerra.

Com efeito, o Governo Dutra, ainda nos anos 40, é freqüentemente identificado pela historiografia como o de uma administração marcada pelo “alinhamento" sistemático à política externa americana. Essa identificação, embora pertinente na sua essência, merece algum reparo ao menos no que se refere ao seu significado econômico e político. O mundo que emergiu da Segunda Guerra Mundial produzia uma grande dissonância entre as percepções da diplomacia americana e brasileira acerca da política internacional e, em função dessa dissonância, grande parte das dificuldades externas do Brasil iriam surgir, uma vez que, desde Rio-Branco, a política externa brasileira tinha por padrão a centralidade das relações com os Estados Unidos. Estrategicamente, não havia dificuldades no "alinhamento", uma vez que os dois países compunham a mesma aliança tradicional em termos regionais e também a grande aliança que começava a ser chamada de "ocidental” em termos de segurança internacional, como havia ficado manifesto na participação efetiva na Segunda Guerra Mundial. A dissonância surgia no campo da diplomacia econômica, onde a "relação especial” do Brasil com os Estados Unidos revelou-se, de fato, um mito.

No Brasil, muito embora nas negociações que antecederam a entrada do País na guerra, o Governo Vargas já houvesse considerado aproximações diplomáticas com outras potências, notadamente Alemanha e Itália, o desfecho da Segunda Guerra Mundial apenas serviu para confirmar a validade da velha "aliança não-escrita”. Se por um lado Alemanha e Itália estavam militar e economicamente derrotadas, por outro, os Estados Unidos emergiam como a grande potência vencedora e única com reservas econômicas em condições de financiar a reconstrução e o desenvolvimento internacional - o que, em última instância, constituía mais uma prova cabal do acerto do velho paradigma.

Outro elemento importante na formação dessa percepção brasileira era a expectativa de que a participação do País na Segunda Guerra Mundial, enviando tropas para se juntar ao esforço de guerra aliado na Europa, deveria resultar em alguma forma de retribuição no pós-guerra, especialmente em termos de suporte financeiro às suas pretensões de industrialização. É óbvio que, do ponto de vista do conjunto das operações militares na Europa, não se esperava que o contingente enviado pelo Brasil pudesse vir a ser um reforço decisivo aos aliados, entretanto, as tropas brasileiras significavam bem mais do que simples apoio simbólico. A adesão do Brasil à causa aliada trazia pelo menos dois elementos importantes: do ponto de vista do ambiente psicológico dos combatentes, a entrada do Brasil significava a incorporação de um aliado de 60 milhões de habitantes e 8,5 milhões de $\mathrm{km}^{2}$ e, conseqüentemente, uma fonte de suprimentos de substancial importância; do ponto de vista estratégico, significava a entrada na guerra do maior país sulamericano cuja situação geográfica (especialmente norte e nordeste) se afigurava 
aos estrategistas americanos como de extrema importância para a defesa da rota do Atlântico, do Mediterrâneo e norte da África. Ao final da guerra, como confirmação dessa percepção, a siderúrgica de Volta Redonda surgia como um símbolo visível desse potencial de cooperação dos Estados Unidos. Stanley Hilton conta que logo após tomar posse o Presidente Dutra teria enviado correspondência para o Presidente Truman propondo um empréstimo de US\$ 1 bilhão, com o que pretendia dar início a um vasto programa de industrialização: foi uma iniciativa frustrada, o empréstimo não se materializou.

Esses fatos ilustram como a percepção americana em relação à América Latina e, em particular ao Brasil, seguiu um rumo diametralmente oposto em razão da conjuntura internacional e da mudança de papel dos Estados Unidos no sistema internacional, que a guerra ajudara a consolidar. Da condição de grande potência regional passam à condição de primeira potência mundial. Na verdade, antes da guerra os Estados Unidos já possuíam os meios para desempenhar esse papel, mas foi somente a partir de meados dos anos 30 que a determinação de assumir claramente um papel de liderança no cenário internacional torna-se cada vez mais manifesta nas instâncias decisórias de Washington. Até então, havia uma verdadeira tradição na política americana no sentido de rejeitarem para si qualquer papel internacional mais protagônico na ordem internacional, entre outras razões, por julgarem que o envolvimento internacional seria prejudicial aos seus interesses, mantendo-se, assim, num relativo isolamento, ainda à sombra da doutrina expressa por George Washington: “... A grande regra de conduta para nós a respeito de nações estrangeiras é, ao ampliar nossas relações comerciais, a de manter com elas a menor ligação política possível” (discurso de despedida, 1796). Na verdade, na prática, mesmo a doutrina Monroe ou a chamada política do "big stick” não constituíram envolvimento com compromissos no sentido de formulação de uma ordem voltada para a manutenção da estabilidade nas relações internacionais, significando apenas intervenções reativas e pontuais. A ausência dos Estados Unidos na Liga das Nações é um reflexo dessa atitude. Não era apenas a herança histórica e a privilegiada soma de recursos naturais que apontavam essa direção para a diplomacia americana, era também a fé liberal que favorecia os mercados e as economias mais fortes e dava sustentação à idéia de que os estados deveriam agir de modo absolutamente soberano. Muitos estudiosos da história das relações internacionais, utilizando os argumentos da abordagem da "estabilidade hegemônica” entendem que, nos anos 20, a recusa por parte dos Estados Unidos de participarem mais efetivamente na administração da economia internacional constituía uma das principais causas da instabilidade comercial, financeira e monetária que se abateu sobre os mercados internacionais e que acabaria por produzir a crise da década seguinte.

A Grande Depressão fora um passo decisivo no sentido de tornar evidente para os Estados Unidos a impossibilidade de ficarem alheios às oscilações e 
problemas da economia internacional. Com efeito, no início da crise, o que ficou conhecido como "beggar-thy-neighbour policy", é geralmente traduzido por "política de arruine-seu-vizinho", mas uma interpretação mais acurada da época indica que a expressão deveria ser mais apropriadamente entendido como "política do salve-se quem puder”, uma vez que os Estados Unidos e todos os outros países às voltas com a recessão apenas tentavam livrar-se da crise que acreditavam ter origem em determinados países ou mercados e que, por via do comércio e das relações monetárias, essa crise estaria sendo "importada”. A ineficácia das medidas protecionistas como a lei Smoot-Hawley, de 1930, mostrava, de modo cada vez mais dramático, que formas institucionalizadas de cooperação internacional seriam necessárias para se devolver a estabilidade econômica internacional. Assim sendo, se regras de convivência haveriam de ser produzidas para se reduzir os efeitos negativos de um meio internacional anárquico, é óbvio que um país com as dimensões e dos Estados Unidos entenderiam que elas deveriam ser produzidas em seu favor, isto é, não deveriam ser danosas aos seus imensos interesses dispersos por mercados, produtos e atividades econômicas.

O envolvimento dos Estados Unidos na Segunda Guerra Mundial constituiu um segundo impulso importante para a mudança de atitude dos formuladores de política de Washington em relação ao entendimento do papel do país como protagonista central na política mundial. Na Europa, não se tratava apenas de alianças políticas que precisavam ser sustentadas, mas tratava-se da própria sobrevivência de uma ordem política, econômica e social coerente com a sociedade americana. De fato, alguns historiadores como Paul Johnson argumentam que o Governo Roosevelt não confiava muito em seus aliados europeus. Às vésperas da Segunda Guerra Mundial, argumenta Johnson, foram destacados embaixadores com visões notoriamente “anti-britânicas” para importantes postos como Londres (Joseph Kennedy) e Moscou (Joseph Davies). Para esses embaixadores, comenta Johnson, a política imperial britânica constituía séria ameaça aos interesses americanos. Por outro lado, a guerra no Pacífico punha em evidência que os Estados Unidos haviam se tornado a única potência efetivamente mundial, isto é, não apenas com interesses espalhados pelos vários continentes, mas também com capacidade de intervir militarmente em qualquer parte do mundo.

Tanto o desenrolar do conflito como também a forma como a Segunda Guerra Mundial encontrou seu desfecho serviram para colocar os Estados Unidos diante de uma posição jamais vista na história política do mundo. Roma havia dominado o mundo "civilizado", que consistia essencialmente dos povos mediterrâneos somando-se mais algumas regiões um pouco mais afastadas na Eurásia e no norte da Europa, mas os Estados Unidos, pela primeira vez na história, haviam se tornado uma potência verdadeiramente global. Todas as regiões do mundo haviam sido, de algum modo, conectadas à civilização eurocêntrica e os Estados Unidos passavam a se constituir no principal ator dessa ordem. Os dados 
econômicos mostram que nos fins dos anos 40 a produção americana havia se tornado várias vezes maior do que a de qualquer outra potência: era sete vezes a da Grã-Bretanha e três vezes a da União Soviética; na verdade a economia americana igualava a soma das economias da Grã-Bretanha, França, Itália, Alemanha, Japão e URSS. Militarmente, a intervenção americana havia sido decisiva na Europa e, no Pacífico, não contou com a concorrência de nenhuma outra potência. Ao todo, em 1944, quando o Brasil envia para a Europa seu primeiro contingente da Força Expedicionária num total de 6.000 homens, entre oficiais e soldados (sobre uma moderna embarcação americana de transporte militar), os Estados Unidos tinham nada menos do que 11 milhões de homens espalhados pelos principais teatros de guerra no mar, em terra e no ar. No pós-guerra imediato, a reestruturação da economia mundial era uma tarefa que ninguém tinha dúvidas de que deveria ser feita sob a liderança americana.

Se a guerra forneceu enorme impulso no sentido dessa redefinição do papel dos Estados Unidos como ator central nas relações internacionais, o fenômeno da guerra fria haveria de ser outro fator decisivo para fortalecer a percepção americana de que a ordem mundial dependia diretamente da ação externa dos Estados Unidos. A guerra fria passaria a ser, ao longo de mais de um quarto de século, o cenário um tanto difuso mas condicionante dentro do qual as principais iniciativas internacionais haveriam de se desenvolver. A rivalidade entre o mundo liberal capitalista e os países socialistas passava a justificar não apenas ações voltadas especificamente para objetivos estratégico-militares, mas justificava também a formulação de programas de cooperação técnica, comercial e financeira. Nesse contexto, o Plano Marshall foi, sem dúvida, a iniciativa mais marcante e de maior envergadura realizada ainda nos primeiros anos da guerra fria. A reconstrução da Europa não era apenas um projeto de natureza econômica, era também parte importante na aplicação de uma doutrina de segurança estratégica e muitas outras iniciativas de menor vulto foram levadas a efeito sob a mesma inspiração em outras partes do mundo consideradas estrategicamente importantes e passíveis de derivarem para a área de influência soviética.

A América Latina em geral, e o Brasil em particular, passam a ocupar uma posição ambígua na política externa americana. Ao mesmo tempo que se reconhecia a importância da região, a percepção americana corrente era a de que ela não demandava grande atenção por parte dos Estados Unidos. Com efeito, a Conferência de Petrópolis (1947), que resultou na assinatura do TIAR (Tratado Interamericano de Assistência Recíproca), mostra que Washington reconhecia efetivamente a importância estratégica da região para a estruturação de um sistema de segurança internacional mas, por outro lado, nessa mesma época as demandas por cooperação econômica recebiam muito pouca atenção. Curiosamente, a tradição de amizade em relação aos Estados Unidos ao invés de servir como motivo de cooperação, no ambiente da guerra fria passava a servir como fator de descaso, 
uma vez que os Estados Unidos deveriam se preocupar não com antigos e “confiáveis” aliados, mas sim com regiões problemáticas, onde a influência de inspiração comunista pró-soviética deveria ser contraposta pela presença americana: Berlim, Turquia, Sudeste Asiático e outras regiões turbulentas do globo se moviam para o centro das preocupações americanas. A Missão Abbynk foi realizada às custas de demoradas e insistentes gestões diplomáticas do Brasil e, mesmo assim, em termos práticos, resultou em muito pouco além de avaliações e propostas de projetos (Plano SALTE). Episódio lembrado por P. R. de Almeida é bastante ilustrativo dessa percepção americana acerca do Brasil e outros países da região: por ocasião da Conferência de Petrópolis, o Brasil fazia gestões para que os Estados Unidos se dispusessem a financiar um programa de desenvolvimento que beneficiasse o Brasil e os demais países da região. O próprio Secretário Marshall teria reagido com certa exasperação argumentando que países como o Brasil e a Argentina, que haviam terminado a guerra como credores, ao invés de estarem pleiteando cooperação financeira dos Estados Unidos deveriam estar preocupados em ajudar a reconstrução da Europa. Esses desenvolvimentos constituem uma espécie de pré-história dos eventos que culminariam com a chamada política externa independente.

A primeira parte do Governo JK foi marcada pelo desenvolvimento de acelerado processo de industrialização de seu Plano de Metas, que previa "50 anos em 5”. O otimismo decorrente do bom desempenho da economia, entretanto, trazia no seu substrato as dificuldades de uma economia que havia se endividado fortemente e que começava a sentir os efeitos, entre outras coisas, do desequilíbrio natural entre o ritmo e prazos desse endividamento e o tempo de maturação dos investimentos. Economias mais maduras podem apresentar prazos menores para a maturação de projetos para o desenvolvimento, entre outras razões, porque, ao contrário dos países pobres, exigem menos investimentos sociais (saúde, educação, saneamento básico, etc.) e também menor volume de investimentos em infraestrutura. Realmente, no caso dos países em desenvolvimento espera-se que os investimentos realizem verdadeiras mudanças no perfil da produção e até mesmo de hábitos de consumo e, assim, o processo exige tempo, tornando mais crucial a necessidade de fundos que operem com prazos mais alongados, genericamente chamados de ajuda econômica internacional. Em suma, o esforço de industrialização acelerada inevitavelmente haveria de se refletir em desequilíbrios nas contas externas, a menos que pudesse dispor de considerável volume de recursos oriundos de programas de ajuda ao desenvolvimento.

Os esforços frustrados de negociação do Governo JK já apontavam para a necessidade de uma nova postura na política externa. O lançamento da Operação Pan-Americana, em 1958, refletiu exemplarmente esses fatos. Geralmente considera-se que essa iniciativa foi de grande valia por seu pioneirismo e por ter servido, segundo muitos analistas, de inspiração para a criação do Banco 
Interamericano de Desenvolvimento (BID) e para a Aliança para o Progresso do Governo Kennedy. Entretanto, para o presente trabalho, talvez seja mais interessante destacar a forma como ocorreu seu lançamento. Ao contrário da prática tradicional, não houve consultas prévias com Washington e os termos da proposta de um vasto programa de desenvolvimento em escala hemisférica foram enviados simultaneamente para todas as chancelarias do Continente provocando uma reação quase irada por parte do Departamento de Estado americano. Apesar de tudo, a mudança na percepção americana sobre as relações com os países ao sul do Rio Grande vai ser mais decisivamente estimulada por dois episódios políticos: os violentos protestos populares na visita do então vice-presidente Nixon a algumas capitais da América do Sul, no início de 1958, e a tomada do poder por Fidel Castro em Cuba em 1959. Ficava claro que os tradicionais aliados do Continente poderiam, perfeitamente, transformar-se em focos de hostilidade à política americana, podendo, inclusive, passar para a órbita de influência soviética.

Esse abandono do chamado paradigma de Rio-Branco vai se tornar mais explícito nos Governos Quadros e Goulart com a chamada Política Externa Independente. É nesse período que a idéia de uma postura externa essencialmente não vinculada aos Estados Unidos vai ganhar densidade através das formulações de personalidades influentes na política externa brasileira, notadamente Santiago Dantas e Araújo Castro. Essas percepções são também fortalecidas por mudanças importantes no cenário internacional, em especial o avanço da descolonização, com a conseqüente formação de inúmeros focos de luta revolucionária na África e na Ásia, tornando praticamente impossível para os Estados Unidos participarem ativamente em todos os focos de luta pelo rompimento de laços coloniais e fornecer ajuda financeira para todas a nações em formação, ávidos dos benefícios da modernidade. A Conferência de Bandung (1955) e a criação da UNCTAD (1964) são episódios que refletem essa mudança e onde são visíveis essa demanda pelos benefícios da modernidade.

\section{O aumento e diversificação da base econômica}

A afirmação de uma diretriz de política externa em que Washington deveria ser considerado apenas como um possível parceiro sofria, no entanto, de um descompasso de meios que iria se revelar em toda sua extensão na inconsistência do Governo Quadros e na fragilidade do Governo Goulart. Quando os militares assumem o poder em 1964, não apenas as contas externas se revelavam incompatíveis com pretensões de independência, mas a própria economia brasileira como um todo revelava-se estagnada enquanto, praticamente todos os setores, quer fossem patronais ou sindicais, manifestavam suas frustrações por um processo de industrialização em vias de interrupção e retrocesso.

Na verdade, a estrutura lógica do modelo de industrialização baseada fundamentalmente no financiamento externo gerava a necessidade de respostas 
relativamente rápidas da economia, que deveriam se refletir nas contas externas, isto é, num primeiro momento haveria o ingresso de capitais (agências de fomento internacional como o Banco Mundial ou bilaterais, em particular a USAID), que permitiria a importação de máquinas, insumos e "know-how" para dar início ao processo de industrialização, incluindo-se aí os investimentos em infra-estrutura. No momento seguinte, o avanço gerado por esse primeiro impulso deveria gerar aumentos na produção e exportação de bens tradicionais e o início da exportação de novos produtos. O problema é que em 1964 a pauta de exportações do Brasil continuava basicamente a mesma do início dos anos 50 com o café e mais uns poucos bens primários representando a base das exportações brasileiras. Mesmo em termos de volume essa assertiva continuava perfeitamente válida. Obviamente não se quer aqui dizer que os governos brasileiros ao longo dos anos 50 devam ser responsabilizados integralmente por esse fato. É notável que as próprias nações industrializadas reconheciam nos fins dos anos 50 as dificuldades existentes na práticas do comércio internacional, que dificultavam a exportação dos países em desenvolvimento. O Relatório Haberler (1958) preparado sob o patrocínio do GATT reconhecia a existência de barreiras que dificultavam as exportações de bens manufaturados e mesmo de excedentes de produtos primários das economias que estavam sendo instadas a realizarem esforço de industrialização. O Relatório recomendava às nações industrializadas a adoção de medidas que facilitassem o acesso aos seus mercados de produtos exportados por países em desenvolvimento. O famoso argumento de Raul Prebisch sobre a existência de uma tendência secular no sentido da deterioração dos termos de troca dos países exportadores de bens primários também se dissemina nessa época, passando a encontrar eco inclusive no âmbito de prestigiosas instituições dos Estados Unidos.

A implementação do conceito de política externa independente vai sofrer uma interrupção com a queda do Governo Goulart, para reaparecer mais tarde, no Governo Geisel sob a denominação de pragmatismo responsável. Na verdade, os governos militares assumem o poder entendendo que, para além da questão imediata do que consideravam "a ameaça comunista”, deveriam investir num projeto de desenvolvimento capaz de transformar o País numa potência, o chamado "Projeto Brasil-Potência” e, nessa perspectiva, a modernização das instituições e a industrialização se apresentavam como base fundamental. A grande dificuldade inicial, e que vai explicar, em grande medida, o que alguns historiadores chamam de retrocesso na implementação de uma política externa independente, era a situação precária da economia brasileira e que se agravara substancialmente nos últimos meses do Governo Goulart. Com efeito, no início de 1964, a economia brasileira não exibia um único indicador positivo: taxas crescentes de inflação, contas públicas deterioradas e taxas de crescimento, geral e setoriais, em franco declínio. Especificamente nas contas externas, a crescente expectativa de inadimplência dificultava qualquer processo de renegociação da dívida ou de 
obtenção de novos empréstimos, isto sem falar no fechamento de linhas de crédito internacional. A política de apoio às ligas camponesas e ao sindicalismo notoriamente de esquerda, além da virtual perspectiva de adoção de medidas de nacionalização de empresas de capital estrangeiro constituíam sinais de que o Brasil poderia perfeitamente derivar para a esfera de influência soviética e, assim, os Estados Unidos tinham ainda outra razão para restringir quaisquer programas de ajuda e cooperação com o Brasil. A Europa, por sua vez, ainda não se encontrava em condições de substituir os Estados Unidos como provedor de fundos para o desenvolvimento em larga escala e, além disso, em termos regionais a América Latina não se constituía em prioridade para a Europa. O fato é que no final do Governo Goulart todas as fontes multilaterais ou bilaterais de crédito estavam fechadas para o Brasil. Ao assumir o Governo, Castelo Branco vai encontrar nos Estados Unidos a única alternativa disponível para buscar recursos para a reorganização da economia e a retomada do esforço desenvolvimentista. A razão para esse apoio, obviamente, decorria das considerações político-estratégicas num contexto internacional condicionado pela guerra fria e não de uma súbita retomada de interesse e confiança no desempenho da economia brasileira. O "realinhamento" com os Estados Unidos se mostrava uma ação coerente com o perfil ideológico do novo governo, que havia sido constituído a partir de um movimento de reação à influência comunista, e também uma ação coerente com a disposição dos formuladores de política de Washington que, desde a administração Kennedy, passaram a assumir a tese insistentemente defendida pela diplomacia brasileira, particularmente na Operação Pan-Americana, de que desenvolvimento e democracia não poderiam ser dissociadas.

Com Castelo Branco, portanto, deixa de existir a problemática dissonância de percepções e, à semelhança do que havia ocorrido no âmbito do chamado Paradigma Rio-Branco, os Estados Unidos se constituem no elemento central de conexão do Brasil com o meio internacional,. A retomada do conceito de independência na política externa vai ocorrer a partir do Governo Costa e Silva, passando a apresentar maior visibilidade a partir do Governo Geisel dentro, contudo, de uma realidade nacional e internacional completamente diferente daquele em que se moveram os governos Kubistschek, Quadros e Goulart. A economia havia se diversificado, o crescimento acelerado dos anos do "milagre econômico" dava outra dimensão às possibilidades econômicas do País, o sistema financeiro fornecia instrumentos e meios para proporcionar maior estabilidade, enquanto a administração pública desenvolvera formas de potencializar a política fiscal como fonte de recursos para dar suporte a projetos de desenvolvimento. No cenário internacional, por sua vez, o processo de descolonização avançara substancialmente com dezenas de novos atores enquanto a crise do petróleo servia para mostrar não apenas a vulnerabilidade das sociedades ao petróleo, mas também a relativa impotência das nações mais fortes perante a ação de um pequeno grupo 
de países politicamente articulados. Assim, tanto do ponto de vista interno quanto externo, as condições haviam se alterado de tal forma que a conexão do País ao meio internacional havia se tornado muito mais complexa tornando inviável qualquer possibilidade de se eleger um único parceiro privilegiado.

O "modelo" de crescimento econômico implementado pelos governos militares disseminava-se pelo mundo, incluindo até mesmo um corpo teórico. Nos anos 60, a "receita" para o desenvolvimento podia ser sinteticamente vista nos "Estágios do Crescimento Econômico" de W. W. Rostow, uma das obras mais influentes da época. Basicamente, a obra dizia que sociedades de economia tradicional podiam industrializar-se e adentrar o mundo da modernidade, típica dos países desenvolvidos, desde que realizasse os investimentos necessários. Também é notável, para efeito da presente análise, que o subtítulo da obra de Rostow não deixava dúvidas quanto à opção política contida no modelo: "A noncommunist manifesto". Seus argumentos centrais referiam-se ao estágio da decolagem (take-off), no qual um aumento nos investimentos produtivos, pela injeção de capitais externos, poderia provocar o desenvolvimento de um ou mais setores manufatureiros mais dinâmicos. O crescimento seria transmitido para o restante da economia a partir desses setores, produzindo mudanças nos padrões industriais em termos de diversificação e de elevação da produtividade a ponto de tornar esse processo auto-sustentado. Do ponto de vista dos reflexos sobre as contas externas desse processo de crescimento, é oportuno lembrar o trabalho do economista francês Raymond Barre, que sintetizava didaticamente "fases" no comportamento do balanço de pagamentos, que seriam percorridas à medida em que uma economia tradicional fosse avançando ao longo dos “estágios” de Rostow. No início, o país seria tipicamente um "devedor novo”, isto é, o país apresentaria superávit na conta de capitais devido à entrada de "ajuda para o desenvolvimento" e déficit na conta de comércio de bens devido à importação de máquinas e insumos necessários à modernização da produção. Numa segunda fase, a conta de capitais continuaria sendo superavitária tanto pela entrada de investimentos diretos quanto pelo recebimento de mais recursos de agências de desenvolvimento. Nessa fase espera-se que alguma manufatura já esteja sendo exportada e que, pelo menos, tenha ocorrido um aumento nas exportações de produtos tradicionais a fim de começar a equilibrar a balança comercial. A partir da terceira fase, denominada por Barre de "credor novo", o país vai entrando efetivamente na "maturidade econômica" onde a conta de capitais deixa de depender das agências de fomento seja porque a economia tornou-se suficientemente atraente aos investimentos produtivos, seja porque o mercado de capitais também já adquiriu maturidade e sofisticação para servir como base capaz de dar continuidade à expansão da economia. Nessa fase, obviamente, a balança comercial deve ser, no mínimo, equilibrada ou coerentemente equilibrada em relação à conta de capitais e ao atendimento do serviço da dívida contraída ainda nas primeiras fases de 
industrialização. A partir daí esse país estaria efetivamente entrando na categoria das economias maduras.

Essa digressão pareceu necessária para analisar o ambiente e as condições econômicas dentro dos quais se desenvolveu o processo de mudança do perfil da política exterior do Brasil. Na verdade, nos fins dos anos 50 e início da década seguinte, a diplomacia econômica brasileira ocupava-se principalmente da negociação de acordos internacionais de produtos de base. Até meados dos anos 60 o volume das exportações brasileiras não atingiam US\$ 3 bilhões e estavam fortemente concentradas no café e em mais uns poucos produtos primários. Essa pauta de exportações revelava a enorme vulnerabilidade da economia brasileira: mercado para as exportações fortemente concentrado (principalmente Estados Unidos) e extremamente vulnerável às oscilações internacionais. Quando Geisel inicia seu governo, as exportações já ultrapassavam a cifra de US\$ 12 bilhões. Nesse período o endividamento externo também havia aumentado na mesma proporção, mas houve, paralelamente, uma substancial diversificação tanto na composição da pauta das exportações (mais da metade passou a ser de manufaturas), como na distribuição dos mercados.

Apesar das dificuldades de um modelo de crescimento que se esgotava e de uma conjuntura internacional pouco favorável, essa nova condição do País com um perfil externo muito mais complexo iria se revelar no âmbito da crise do anos 70. Com efeito, pode parecer um tanto paradoxal que a versão mais efetiva de uma "política externa independente" tenha se consolidado exatamente num período de dificuldades crescentes. Agora, passadas as apreensões e perplexidades da época percebe-se que a chamada política do “pragmatismo responsável” tinha efetivamente um conteúdo operacional que procurava adequar as demandas de uma economia que havia avançado substancialmente na industrialização, mas que apresentava ainda inúmeros pontos de vulnerabilidade que se mostravam particularmente agudas no contexto das turbulências provocadas pela crise do petróleo. Essa adequação não poderia ser feita dentro dos padrões tradicionais uma vez que mudanças importantes ocorriam no contexto internacional. A guerra fria não acabara, mas o fracasso americano na Guerra do Vietnã não significara apenas um fracasso militar, mas representara também um duro golpe na percepção do povo americano e de suas lideranças a respeito de seu papel no mundo. Tanto nas questões de segurança, quanto no esforço de desenvolvimento internacional, os anos 70 marcaram um período de redução nas expectativas americanas em relação ao meio internacional. Na verdade, contrariando o otimismo de John Kennedy, Walter Lippmann, já em 1961, afirmava “A realidade é que, na década de 1960, os Estados Unidos não podem arcar com a mesma proporção - e aqui friso o termo proporção - do ônus da segurança coletiva e do desenvolvimento industrial que suportaram durante os últimos dez anos”. 
O quarto de século que antecedeu a crise do petróleo é visto como um "golden age" no pós-guerra - um período de elevadas taxas de crescimento, que se espalharam por todo o mundo, incluindo-se aí a consolidação da recuperação econômica da Europa e do Japão. Além disso, em fins dos anos 60, o relatório preparado pela Comissão Pearson listava meia centena de países em desenvolvimento que, por uma década, vinham mantendo taxas de crescimento real acima de $2 \%$ ao ano. Desse modo, não era apenas a economia brasileira que se expandia e se diversificava, mas a própria economia mundial também se expandia abrindo alternativas e reduzindo substancialmente o peso relativo da economia americana.

Na metade dos anos 70, mesmo com o início da crise do petróleo, havia uma percepção generalizada de que o País já havia atingido o nível de sustentabilidade do desenvolvimento preconizado por Rostow, acreditando-se que a crise era passageira e que os efeitos imediatos poderiam ser contidos satisfatoriamente através de uma política mais rígida de controle das contas externas. Os gastos com a conta petróleo, que antes de 1973 já constituíam o item mais importante na pauta de importações em face do grande avanço no processo de industrialização, passaram a se elevar rapidamente pressionando as contas externas. Antes do primeiro choque do petróleo (1973) o Brasil gastava menos de US\$ 500 milhões em importação de petróleo, em 1975 essa conta já havia atingido US\$ 2,7 bilhões e continuou se elevando até 1981, quando atingiu a cifra de US\$ 10,5 bilhões. Apesar de tudo, as dificuldades geradas pela conta petróleo não implicaram uma volta do Brasil ao círculo de influência mais direta dos Estados Unidos, a exemplo do que havia ocorrido no pós-guerra imediato e nos primeiros anos dos governos militares, ao menos por duas razões, além daquela mencionada no parágrafo anterior. A primeira decorria da grande concentração das compras de petróleo sobre os países do Oriente Médio, notadamente Iraque e Arábia Saudita, que, no auge da crise vão responder por cerca de $90 \%$ das importações brasileiras de petróleo. A segunda razão decorria do fato de que esse período coincide com a reorganização do que foi convencionado chamar de ordem de Bretton Woods e, assim, os déficits em contracorrente de países como o Brasil foram sendo sistematicamente financiados por empréstimos feitos junto a bancos privados, o que foi possível não apenas pela "desregulamentação” dos mercados financeiros, mas também pelo fato de que havia grande liquidez no âmbito das instituições financeiras privadas a ponto dos juros reais serem muito baixos (negativos na primeira metade dos anos 70 e algo em torno de $0,5 \%$ ao ano na segunda metade da década). As razões para essa abundância de dólares nos mercados financeiros eram várias, entre elas a reciclagem dos petrodólares (superávits dos países exportadores de petróleo) e a recessão nos países industrializados. Nesse contexto, uma diplomacia brasileira de sustentação das posições americanas no Oriente Médio fazia pouco sentido, enquanto, no plano financeiro, a abundância de dólares 
nos mercados internacionais privados ofereciam uma alternativa a uma possível demanda por ajuda financeira americana ou das fontes oficiais multilaterais. $\mathrm{Na}$ verdade, o volume do endividamento internacional e dos déficits em conta corrente, que se acumulavam nas contas dos países em desenvolvimento, superavam em muito a capacidade financeira do Fundo Monetário Internacional.

Obviamente, razões estruturais importantes poderiam ser adicionadas a esse quadro. A expansão das economias, notadamente do Japão no extremo Oriente e dos principais centros industriais e financeiros da Europa, associada à corrosão da bipolaridade ideológica e estratégica, que se acentua no cenário internacional após o conflito no Vietnã, oferece um cenário internacional de múltiplas possibilidades, onde a agenda de negociações internacionais deixa de ser tão concentrada em Washington. Nos anos 70, a mobilização de um considerável número de países por uma "Nova Ordem Econômica Internacional” reflete, em larga medida, esse ambiente. Desde a formação da UNCTAD em 1964, disseminase a idéia de que os países em desenvolvimento deveriam unir-se em torno de um conjunto comum de reivindicações que, em última instância, significaria transformar as regras e procedimentos em vigor nas relações econômicas internacionais. Essa percepção vai tornar-se mais generalizada com o desencadeamento da crise do petróleo, que instaura a noção de que a dicotomia “leste-oeste” deveria ser substituída pelo “diálogo norte-sul”. O poder de barganha revelado pelos países produtores de petróleo era um indicativo de que outras “commodities” poderiam proporcionar aos países instrumentos de pressão igualmente eficazes. Em conjunto, esse poder de barganha deveria se empregado no estabelecimento de novos regimes para o comércio e para os fluxos de capitais internacionais. O Brasil jamais se associou como participante ativo nesse movimento, que, em poucos anos, iria revelar-se inconsistente entre outras razões, porque os países produtores de petróleo não se dispuseram a apoiar com recursos o movimento por uma nova ordem internacional. Entretanto, países como o Brasil não deixavam de perceber que a realidade internacional vivia grandes mudanças e que, de qualquer modo, suas necessidades, mesmo as mais imediatas, não poderiam ser tratadas a partir de alianças privilegiadas. Ainda que pudesse se apresentar como a alternativa mais incômoda, a ação externa brasileira, portanto, deveria passar a incluir múltiplos atores e múltiplas instâncias de negociação.

Episódio marcante nesse período foi a negociação do Acordo Nuclear com a Alemanha. Dentro do quadro exposto, o interesse brasileiro pelo domínio de tecnologias consideradas estratégicas aumentou substancialmente. Dominar o ciclo nuclear não constituía apenas estar em condições de manejar uma tecnologia que poderia, eventualmente, servir de "passaporte" para um novo posicionamento estratégico de um país que se pretendia potência de expressão internacional mas, em face das dificuldades, dominar a tecnologia nuclear significava também reduzir vulnerabilidades para a indústria e a própria sociedade brasileira. Com efeito, o 
acordo foi firmado em meio a inúmeros projetos e programas de desenvolvimento de capacitação tecnológica na produção e uso de fontes energéticas alternativas, onde se destacava o PRO-ÁLCOOL e próprio programa de construção da capacitação nuclear. Pode-se dizer que, em larga medida, as dificuldades com a diplomacia do Governo Carter a esse respeito decorriam novamente da dissonância de percepções no sentido inverso daquele ocorrido no pós-guerra imediato. A iniciativa brasileira era entendida como sendo basicamente de ordem estratégica no sentido militar, ainda mais considerando as relações econômicas do Brasil com o Oriente Médio. Não se considerava que a crise do petróleo havia exposto a grande vulnerabilidade da economia despertando preocupações com a segurança e a estabilidade econômica do País. Não se considerava também que as dificuldades cambiais empurravam o Brasil para o emprego em larga escala do mecanismo do "countertrade", uma espécie de versão moderna e sofisticada de escambo, o que explicava o grande aumento na compra de petróleo no Oriente Médio. A negociação do Acordo Nuclear com a Alemanha punha também em evidência outra faceta da crescente multipolarização da economia mundial: havia outros centros capazes de oferecer não apenas mercados, mas também tecnologias avançadas.

No plano das questões políticas tanto a atitude brasileira em relação à descolonização, que vai colocar o Brasil em posição antagônica com o Governo de Portugal no caso de Angola, quanto a reaproximação com a China continental, vão se revelar efetivamente "pragmáticas”. Em Portugal a política colonial herdada de Salazar vai sendo rapidamente abandonada, iniciando-se esforços de negociação para uma Angola independente onde o Brasil poderia oferecer espaço adicional de negociação, ao se tornar uma alternativa neutra, capaz de equilibrar a influência soviética que dava sustentação às tropas cubanas em Angola. No caso da China, o próprio Governo Nixon, tendo Henry Kissinger por Secretário de Estado, vai iniciar o processo de reaproximação diplomática que iria culminar, inclusive, com a substituição da China de Formosa pela China Continental nas Nações Unidas. Desse modo, é curioso notar que a diplomacia americana, ao mesmo tempo que praticava a "abertura" em relação ao bloco comunista, olhava com suspeição os movimentos da política externa do Brasil, que apenas procurava ampliar os horizontes de suas opções internacionais de modo a dar mais consistência às suas iniciativas políticas num ambiente interno e externo muito mais diversificado e complexo.

\section{O Brasil como “global trader”}

O “pragmatismo responsável” do Governo Geisel já havia revelado que o Brasil apresentava um perfil bastante diferente de um país tipicamente “subdesenvolvido", inclusive no que concerne às relações exteriores. Uma pauta muito mais diversificada no comércio, um avanço substancial na produção indus- 
trial e uma considerável expansão dos setores de serviços, incluindo-se o setor financeiro, realmente tornavam sem sentido a identificação do Brasil com os estereótipos tradicionalmente associados aos países em desenvolvimento, caracterizados como exportadores de uns poucos bens primários e importadores de manufaturas. Ao longo dos anos 80, essas novas características do quadro econômico e político do País, que proporcionam as bases para a sua conexão externa, irão formar um quadro ainda mais complicado não apenas em função das turbulências associadas às transformações na economia e na política internacional que se aceleravam, mas também em razão das mudanças políticas que se verificavam no plano doméstico, notadamente o processo de redemocratização traduzido na eleição de um candidato da oposição, na liberdade de manifestação e associação política, na elaboração de uma nova constituição e na retomada de eleições diretas para todos os níveis do executivo e legislativo.

Na ordem internacional, a queda do Muro de Berlim e o colapso da União Soviética são considerados como os episódios que marcaram o fim da guerra fria. É óbvio que essa caracterização tem apenas sentido simbólico uma vez que fenômenos tão complexos como a guerra fria não podem estar associados apenas à existência de governos e regimes ou a fatos episódicos, por mais significativos que possam parecer. Assim como o surgimento da bipolaridade estratégica internacional ainda não estava claro no final da Segunda Guerra Mundial, muito embora os elementos estruturais que lhe dariam sustentação por várias décadas já estivessem presentes, também o colapso do bloco socialista constituiu apenas um episódio, ainda que de enorme repercussão, na longa agonia de um padrão prevalecente na ordem internacional. Na verdade, grande parte da discussão desenvolvida neste trabalho até o momento forma um conjunto de dados e desenvolvimentos subjacentes ao processo de surgimento de um novo perfil para o sistema internacional genericamente denominado de globalização pelas diferentes correntes de análise das relações internacionais.

Um artigo de Peter Drucker e um livro de autoria de Richard Rosecrance, publicados em meados da década de 80 , ilustram com muita propriedade as preocupações e o sentido das grandes transformações que ocorriam na ordem internacional. Peter Drucker, analisando as mudanças na economia mundial, destacava a ocorrência de um "descolamento" entre a produção industrial, o consumo de matérias primas e o mercado de trabalho. Nas transações internacionais identificava também o "descolamento" entre o comércio e os fluxos financeiros. Nessa época já era possível perceber, portanto, que o crescimento da produção não constituía mais garantia de emprego e que os fluxos internacionais de capital não obedeciam necessariamente o sentido do comércio, características importantes na composição do quadro do que, genericamente nos anos 90 , viria a ser chamado de "globalização". 
A crise dos anos 70 havia evidenciado as dificuldades de uma estratégia de crescimento para a economia internacional que se esgotava, assumindo contornos mais dramáticos nos países da periferia que haviam avançado mais no esforço de industrialização. Com efeito, a disseminação generalizada da industrialização, associada a um processo de endividamento em larga escala, encontrou na turbulência do mercado de petróleo um fator profundamente desequilibrador. Essa turbulência ajudou a expor a vulnerabilidade das economias emergentes do “Terceiro Mundo", ao combinar a incapacidade dos mercados centrais de absorver exportações dos países em desenvolvimento com crescentes déficits comerciais decorrentes do aumento explosivo dos gastos desses países com a importação de petróleo. Por outro lado, a crise serviu também para incentivar duas outras mudanças importantes para a formação do quadro de "descolamento" de que falava Drucker e que vai ajudar a compor a base da globalização: acelerou a liberalização dos mercados financeiros, estimulando o deslocamento da liquidez internacional para a instância privada, e propiciou um impulso sem precedentes aos investimentos em novas tecnologias.

Nesse contexto de mudanças que ocorriam na própria estrutura da economia mundial, os Estados procuravam formular respostas capazes de adaptar suas empresas e instituições aos novos padrões da disputa por níveis de produtividade em condições de competir satisfatoriamente nos mercados internacionais mais dinâmicos. A formulação de mecanismos que pudessem reforçar a posição nacional incluía não apenas políticas de incentivo à indústria e aos investimentos em pesquisa e desenvolvimento, mas incluía também considerável revisão das ações no plano externo.

No Brasil, os anos 80 vão ser marcados pela democratização no plano político e pelos constrangimentos impostos pela dívida externa, que se constituía na forma mais expressiva das dificuldades de um "modelo de crescimento" que se esgotava. A estratégia de substituição de importações havia produzido frutos impulsionando o processo de industrialização do País no pós-guerra, no entanto, as crises dos anos 70 e 80 mostravam claramente a inviabilidade da continuação dessa estratégia seja pelo esgotamento das fontes de recursos financeiros para o desenvolvimento, seja pela impossibilidade de aumentar as exportações significativamente no curto prazo. As fontes oficiais de recursos para o desenvolvimento eram dependentes essencialmente dos Estados Unidos, que encontravam grandes dificuldades para manejar seus crescentes déficits comerciais, enquanto a expansão das exportações brasileiras era dificultada não apenas pela relativa estagnação das principais economias, mas também pela crescente competição comercial por parte de todos os países, independentemente do nível de industrialização, além, naturalmente, de políticas protecionistas, explícitas ou camufladas, praticadas pelos países industrializados. 
Episódio marcante na formação da percepção relativa à ineficácia ou esgotamento da estratégia de substituição de importações foi o caso da política de reserva de mercado para a indústria de informática. Apoiada por uma aliança dos setores nacionalistas de esquerda e de direita, a lei de reserva de mercado foi aprovada pelo Congresso e posta em vigor em 1984. Entendeu-se que a área de informática constituía um elemento estratégico para a autonomia industrial, e mesmo política do País, e pretendeu-se que esse dispositivo seria capaz de permitir o desenvolvimento de uma indústria nacional de informática ampla e autônoma. Ao final dos anos 80, a ineficácia dessa proteção já se tornara evidente, uma vez que o dinamismo da inovação tecnológica e o caráter essencialmente interativo da indústria da informática faziam com que o protecionismo se constituísse em verdadeiro entrave ao seu desenvolvimento. Percebia-se também que, em todo o mundo, era cada vez mais generalizada a disseminação dos recursos de informática para todos os segmentos industriais e de serviços, alterando os padrões de competitividade e ampliando as possibilidades de novos serviços e novos produtos. Até mesmo a agricultura passava a agregar recursos oferecidos pela informatização às suas mais variadas atividades. Assim, esse instrumento de proteção da indústria nacional, criado para promover o desenvolvimento de uma área considerada chave, em última instância, acabou por representar um entrave para a competitividade de toda a economia e não apenas do setor específico da indústria da informática.

Outro fato que contribuiu para formar a percepção dos muitos problemas gerados pelo protecionismo generalizado, decorreu da experiência mal sucedida dos “choques” de estabilização. O Plano Cruzado, obteve grande sucesso nos primeiros meses mas rapidamente revelou-se incapaz de assegurar a estabilidade da moeda. Os planos que se seguiram também tiveram o mesmo destino: a redução abrupta das taxas de inflação era, invariavelmente, seguida de uma nova escalada dos preços. O fechamento da economia constituía um fator importante na inviabilização desses planos, uma vez que o mercado internacional, além de funcionar como regulador dos preços no longo prazo, no curto prazo serve como provedor da demanda adicional que eventualmente possa ocorrer nas economias nacionais. Mesmo o Plano Collor, que pretendeu evitar as pressões da demanda através do congelamento dos ativos financeiros, também teve eficácia muito curta, apenas confirmando a inviabilidade de qualquer plano econômico que não considere a economia do País como integrante de uma realidade global. Inegavelmente, o fato da economia brasileira ser hoje muito mais aberta tem sido um fator que tem contribuído bastante para a manutenção da estabilidade da moeda desde 1994..

No fim dos anos 80 e início da década de 90, a busca de novos parâmetros para a política externa não era apenas uma tarefa a ser empreendida pelo Brasil. Os demais países que, como o Brasil, de algum modo haviam avançado na industrialização, passaram a enfrentar problemas semelhantes não apenas nas suas contas externas, mas também no que se referia à impossibilidade de manter seus 
mercados internos protegidos da concorrência internacional. Cada país, como no caso da indústria da informática do Brasil, vivia sua própria experiência dos efeitos negativos das práticas protecionistas herdadas da estratégia de substituição de importações. Provavelmente o caso mais amplo e dramático dos efeitos do fechamento dos mercados domésticos tenha sido o da União Soviética e dos países do antigo bloco socialista, cujo colapso revelou a enorme extensão do atraso tecnológico vivido por essas sociedades. Mesmo as nações industrializadas passaram a buscar novos instrumentos e formas de inserção na dinâmica de uma economia mundial marcada por sistemas interativos altamente complexos. Nos Estados Unidos foi muito sintomática a derrota de George Bush para Bill Clinton. Enquanto Bush ainda desfrutava a grande popularidade conseguida na Guerra do Golfo, Bill Clinton, apostava num programa que priorizava a recuperação da competitividade internacional das indústrias americanas, inclusive como forma de combater o desemprego.

Em termos multilaterais, a amplitude efetivamente global e interdependente das transações internacionais se traduzem tanto nas dificuldades nas negociações ao longo da Rodada Uruguai, quanto no seu desfecho, que acabou por produzir a decisão de implementar uma Organização Mundial do Comércio, com normas mais definidas e com instrumentos institucionais mais efetivos para assegurar o cumprimento das regras estabelecidas no âmbito multilateral. Entretanto, ao mesmo tempo que as novas condições da economia internacional exigiam um sistema de articulação comercial menos fluida do que o GATT (cujo principal instrumento de ação eram as rodadas de negociação), o novo multilateralismo, fruto das mudanças estruturais do sistema internacional, vai estimular paralelamente o desenvolvimento de sistemas regionais.

Com efeito, a Rodada Uruguai havia tornado evidente a inadequação do tradicional entendimento da idéia de liberalização comercial simplesmente como liberalização tarifária e a inclusão de temas como serviços, finanças e propriedade intelectual nas discussões da Rodada refletem amplamente esse fato. Uma característica marcante do GATT era sua relativa tolerância em relação às políticas nacionais, em grande parte porque nas rodadas de negociação anteriores raramente as discussões punham os países industrializados em campos opostos. Na Rodada Uruguai, no entanto, as divergências entre países industrializados vão surgir com freqüência como no caso dos produtos agrícolas e dos acordos setoriais que envolviam parte substancial do comércio mundial que passava a ser conduzido intra-firmas. Além disso, outra questão complicada para ser resolvida no âmbito das negociações multilaterais era a inclusão das medidas de política doméstica que afetavam o comércio na forma de restrições ou subsídios disfarçados.

Embora alguns analistas considerem que os resultados da Rodada Uruguai apenas delimitaram novas formas de protecionismo que seriam permitidas, aparentemente, nenhum país ou grupo de países saiu suficientemente satisfeito 
com os acordos alcançados na Rodada e, em grande medida, a principal “cláusula de escape” que se apresentava aos países passava a ser a da tolerância em relação aos sistemas regionais no âmbito dos quais muitas exceções poderiam ser praticadas. Em 1994, lembrava o Diretor Geral do GATT, todas as então 115 Partes Contratantes do GATT eram membros de pelo menos um acordo preferencial. Assim, a formação de blocos passou a ser um recurso na busca da inserção na ordem internacional globalizada, independente do nível de industrialização e da dimensão do país. O arranjo regional, em alguns casos, poderia ser instrumento para assegurar a abertura de mercados importantes, em outros, especialmente nos casos dos países que por longo tempo praticaram políticas como a da substituição de importações, poderia servir de base de aprendizado e adaptação para as novas condições da convivência internacional. Mesmo no caso americano, ao lado do inevitável envolvimento dos Estados Unidos com as muitas questões e regiões consideradas críticas no mundo, e apesar de todos os fatores que o distinguem como a economia mais produtiva e pujante do mundo, o país vai procurar suporte no âmbito regional, primeiro através da criação do NAFTA e depois propondo um projeto mais amplo de criação de um grande mercado comum hemisférico. A Europa, por sua vez, passa a imprimir novos rumos ao seu processo de integração regional e os acordos de Maastricht são o produto mais visível dessa orientação, com vistas à ampliação e aprofundamento da União Européia. São também notáveis as suas iniciativas no sentido de fomentar acordos com outros blocos regionais como o MERCOSUL.

É nesse contexto que se pode compreender tanto o interesse brasileiro na formação e desenvolvimento do MERCOSUL, na condição de arranjo regional prioritário para o País, quanto os esforços de ampliação de opções internacionais em outros continentes. Ao contrário do que ocorria com a ALALC, do início dos anos 60, quando toda a América Latina significava muito pouco para o comércio exterior brasileiro (assim como para os demais países da região), na atualidade, a América do Sul e, em especial, os países do MERCOSUL passaram a ter um peso muito mais significativo para os países da região. Para o Brasil, além do volume crescente de comércio com a região, vale notar também que a composição da pauta de comércio regional inclui uma proporção muito maior de bens com grande conteúdo tecnológico. Em termos gerais, o comércio exterior brasileiro hoje se apresenta muito menos concentrado. Os Estados Unidos que, por muito tempo, chegaram a representar bem mais da metade de todas as exportações brasileiras, hoje, apesar de ser o maior parceiro comercial unitário, tem um peso significativamente menor no comércio exterior brasileiro. Em meados dos anos 80, as exportações brasileiras para os Estados Unidos somavam 27,2\% do total, em 1994 essa proporção havia se reduzido para 20,6\%, muito embora em valores, as vendas do Brasil para os Estados Unidos tivessem aumentado em US\$ 2 bilhões no período. O comércio regional passou a ser elemento importante na diversificação 
do mercado externo brasileiro: em meados da década de 80 apenas 4,7\% das exportações brasileiras se dirigiam aos países do MERCOSUL, mas em 1994 essa proporção havia triplicado atingindo 13,7\%. Cabe notar que o mesmo fenômeno ocorria com outros países da região. Para a Argentina, por exemplo, no mesmo período, os países do MERCOSUL como mercado para suas exportações passaram de $9,5 \%$ para nada menos do que $30,4 \%$.

Os dados econômicos refletem a tendência geral do posicionamento do Brasil no plano externo. Sob todos os ângulos a nova conjuntura passou a indicar que o País deveria assumir uma postura mais atuante. Nas questões de segurança internacional, por exemplo, a inclusão do Brasil como membro permanente do Conselho de Segurança da ONU passou a ser avaliada também nesse contexto. Essa possibilidade já havia sido considerada pelos Estados Unidos durante as negociações de Dumbarton Oaks em 1944. O Presidente Roosevelt chegou a discutir a inclusão do Brasil na condição de sexto membro permanente do Conselho de Segurança, mas não obteve a concordância das duas outras grandes potências com as quais os Estados Unidos negociavam os termos do pós-guerra. Tanto a GrãBretanha quanto a União Soviética, por diferentes razões, consideravam que a inclusão do Brasil iria desequilibrar o jogo de forças no âmbito do Conselho. De sua parte, o Presidente Roosevelt julgou inoportuno insistir nessa inclusão em face das muitas questões internacionais que o preocupavam (entre as quais se destacava a guerra no Pacífico) e que, em sua opinião, exigiam a cooperação dos dois grandes aliados.

O retorno da discussão de uma possível inclusão do Brasil no Conselho de Segurança da ONU como membro permanente se dá no âmbito de uma conjuntura internacional marcada por grandes transformações, onde a reforma da organização reflete a necessidade de adequar a entidade a essas mudanças. Assim, do mesmo modo que na economia internacional, que durante três décadas havia entendido o termo cooperação econômica como ajuda ao desenvolvimento, passando agora a entender essa expressão como negociação e competitividade, na política, inclusive em questões de segurança, a cooperação internacional passa a significar, cada vez mais, repartição de responsabilidades e de custos. Nesse quadro de mudanças e de revisão de papéis, onde a individualização das oportunidades e dos riscos e a redistribuição de responsabilidades constituem características marcantes nas negociações internacionais, há muito pouco espaço para "free-riders”. Em outras palavras, tornou-se inevitável que um país com as dimensões do Brasil tenha que assumir o papel de um ator mais protagônico, ainda que esse papel seja desempenhado de modo discreto e até mesmo com certo enfado. 


\section{Resumo}

A política externa brasileira, de 1958 a 1998, atravessa três grandes períodos ou mudanças em suas orientações e formas de atuação. Numa primeira fase, herdada ainda do período anterior do imediato pós-guerra e mesmo anterior a ela, ela vive ainda o "paradigma Rio Branco", isto é, orienta-se basicamente e busca manter relações especiais com a principal potência hemisférica. No período do regime militar, assiste-se a uma ampliação do quadro de relacionamento externo, contemporaneamente a grandes mudanças na estrutura econômica do País. Na fase recente, finalmente, emerge a importância do multilateralismo econômico, no contexto da globalização. Essas inflexões são analisadas colocando-se lado a lado mudanças na conjuntura internacional e nas condições políticas e econômicas do País.

\section{Abstract}

Brazilian foreign policy has known three main shifts from 1958 to the present. Initially, confirming a trend confirmed in the aftermath of World War II but that was in place since the beginning of the century, the policy follows what could be called the "Rio Branco paradigm", that is the seach for a special relationship with United States. Afterwards, during the military dictatorship, the foreign policy enters a period of diversification of external relationships, in the framework of big changes in the economic basis of the country. More recently, arises the centrality of economic multilateralism for the continuing international insertion of Brazil, in the context of globalization. These inflexions are described together with discussions of the main changes in the international scenario and in the socioeconomic and political conditions of Brazil.

Palavras-chave: Brasil, política externa, diplomacia, transformações econômicas.

Key-words: Brazil, foreign policy, diplomacy, economic changes. 